\title{
QUALIDADADE DO AR “MARROM” NO MUNICIPÍO "VERDE": O CASO PARAGOMINAS
}

Brendo Luiz Araújo Alves - brendo_luiz96@ hotmail.com

Universidade do Estado do Pará

Christian Guaniere Freita da Silva - rchristian1bj@gmail.com

Universidade do Estado do Pará

Lucas Henrique Fernandes Resueno - lucasresueno96@gmail.com

Universidade do Estado do Pará

Vitor Glins da Silva Nascimento - glins1996@ gmail.com

Universidade do Estado do Pará 


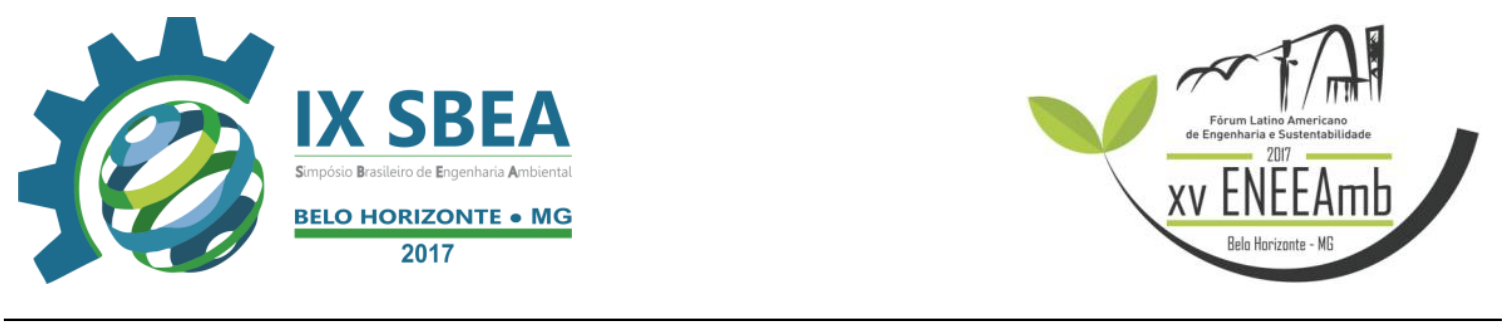

\section{RESUMO}

Os efeitos da poluição são observados desde a antiguidade, mas o marco desta intempérie foi com a Revolução Industrial, na qual a população foi afetada em proporções imensuráveis. Nas últimas décadas, a urbanização acelerada ocasionou o aumento exacerbado no consumo de energia e nas emissões oriundas da queima de combustíveis fósseis. Diante disto, a poluição destaca-se como um dos entraves ambientais mais complexos, a qual agride o sistema respiratório humano, além de impactar de forma negativa sobre a fauna e flora. Dessa forma, o monitoramento da qualidade do ar, como no caso o município de Paragominas que apresenta o selo de município verde, se porta como uma das principais ferramentas para a manutenção de níveis seguros de poluentes na atmosfera. O objetivo do estudo foi analisar a qualidade do ar no município de Paragominas através de relatos e opiniões de profissionais atuantes na área ambiental, bem como verificar se as legislações vigentes estão sendo cumpridas; além de comparar a qualidade do ar atualmente com a de décadas passadas. A metodologia utilizada nesta pesquisa exploratória foi observativa, sistemática, direta, in situ e com dados pretéritos; complementada com pesquisa bibliográficas e entrevistas semiestruturadas que foram aplicadas à empresas de consultoria ambiental e órgãos competentes, como a Secretaria Estadual de Meio Ambiente e Sustentabilidade (SEMAS) do Estado do Pará. O estudo foi realizado no município de Paragominas, situado na região do nordeste do Pará, possuindo como principal via de comunicação e transporte a Rodovia Belém-Brasília (BR-010). Os dados obtidos indicam que o ambiente apresenta melhoria, se comparado as três últimas décadas, porém o mesmo não se encontra em um patamar excelente e que se enquadre no cenário "verde" no qual o município se insere. De acordo com os dados das entrevistas, revelou-se um conflito de ideias e opiniões no que se refere a atual condição do ar da cidade. Dessa forma, evidencia-se que apesar da qualidade do ar no município ter melhorado, as legislações vigentes não estão sendo cumpridas na sua totalidade, como no caso da lei municipal n. 644:2007, que se refere a Política Municipal de Meio Ambiente.

Palavras-chave: Poluição, Monitoramento, Qualidade do Ar. 


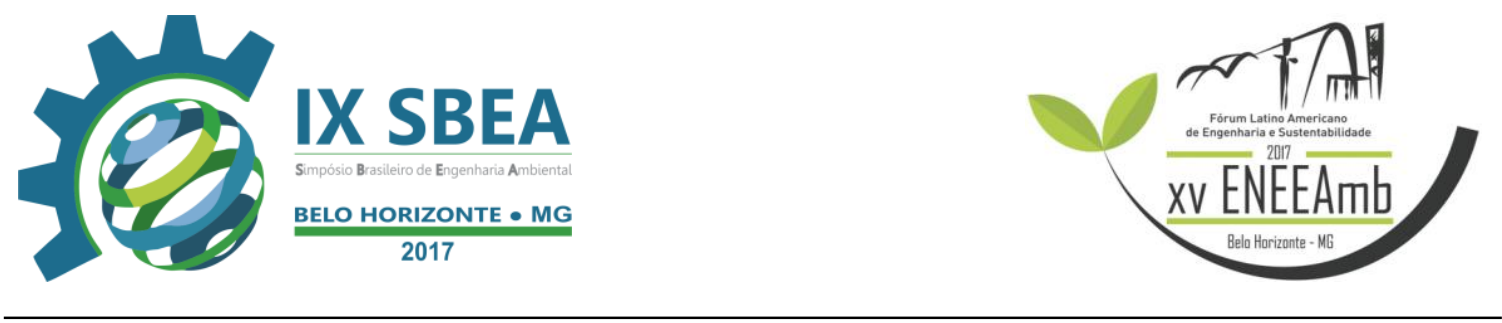

\section{INTRODUÇÃO/OBJETIVO}

Os efeitos da poluição são retratados desde a antiguidade, porém, foi somente com o advento da revolução industrial que a poluição afetou a população em proporções imensuráveis. A urbanização acelerada presente em todo o planeta ocasionou o aumento excessivo no consumo de energia e, também, nas emissões procedentes da queima de combustíveis fósseis por fonte fixas, como no caso as indústrias, e por fontes móveis como os veículos automotores (ARBEX et al., 2012).

Em função do crescimento exacerbado das populações nas áreas urbanas e a intensificação da necessidade de consumo, as indústrias, em geral, aumentaram consideravelmente em quantidade, variedade de produtos e áreas de atuação. Contundo, a responsabilidade com o meio ambiente degradado, principalmente na área referente a qualidade do ar, não obteve o devido valor, ocasionando consequentemente, problemas ambientais de grandes dimensões e muita das vezes, irreversíveis (LEAL et. al., 2008).

Desse modo, nas áreas urbanas, enormes quantidades de compostos químicos são lançadas para atmosfera por intermédio das indústrias, veículos e outras atividades antrópicas. Cerca de 3000 compostos distintos já foram identificados na atmosfera oriundo das ações humanas e, de maneira geral, existe um grupo de poluentes que desempenham a função de indicadores da qualidade do ar, que são regulamentados e de uso universal: Material Particulado (MP), Monóxido de Carbono (CO), Ozônio $\left(\mathrm{O}_{3}\right)$, Dióxido de Enxofre ( $\mathrm{SO}_{2}$ ) e Óxidos de Nitrogênio (NOx) (GUARIEIRO et. al., 2011).

Portanto, altas emissões de gases poluentes atmosféricos representam grande risco a saúde humana, prejudicam a flora e a fauna, além de destruir e prejudicar monumentos históricos e construções modernas. Estes efeitos ocorrem, principalmente, em aglomerações urbanas, pois são nestas regiões que apresentam grande variedade e quantidade de poluentes que afetam a saúde de muitos indivíduos, devido à alta densidade populacional nos centros urbanos (KLUMPP et al., 2001).

Neste contexto, atualmente, os gases e partículas ultrafinas resultantes, principalmente, da queima parcial de combustíveis fósseis em automóveis, como por exemplo o diesel, representam um dos essenciais fatores responsáveis pelo alto índice de asma brônquica e diversas doenças alérgicas distintas em populações que residem em 
locais ou áreas com a maior concentração de poluentes, ou seja, áreas mais poluídas (MOURA et al., 2008).

A poluição do ar destaca-se como um dos entraves ambientais mais complexos, onde agride o sistema respiratório humano, podendo provocar doenças crônicas tais como a asma, bronquite, infecções no pulmão, enfisema pulmonar e alergias, sendo responsável pela morte de 3,6 milhões de pessoas no mundo em 2012. Dessa forma, o monitoramento da qualidade do ar, como no caso o município de Paragominas que apresenta o status de município verde, se porta como uma das principais ferramentas para a manutenção de níveis seguros de poluentes na atmosfera (SEMA, 2008).

O objetivo do estudo foi analisar a qualidade do ar no município de Paragominas por intermédio de relatos e opiniões de profissionais atuantes na área ambiental, bem como verificar se as legislações pertinentes em vigor estão sendo cumpridas; além de comparar a qualidade do ar há décadas e atualmente.

\section{METODOLOGIA}

A metodologia aplicada nesta pesquisa exploratória foi a observativa, sistemática, direta, in situ e com dados pretéritos. Complementada com pesquisa bibliográfica (links eletrônicos e artigos científicos) e entrevistas semiestruturadas que foram aplicadas a empresas de consultoria ambiental e órgãos competentes, como a Secretaria Estadual de Meio Ambiente e Sustentabilidade (SEMAS) do estado do Pará, cujo foco do estudo fosse similar ao do presente artigo. A pesquisa exploratória tem o intuito de permitir maior familiaridade com determinado problema, ou seja, explicitá-lo, como é o caso do deste artigo em relação a qualidade do ar no município de Paragominas.

\section{1 ÁREA DE ESTUDO}

O estudo foi realizado no município de Paragominas, situado na mesorregião nordeste do Pará, tendo como principal via de comunicação e transporte a Rodovia Belém- Brasília (BR-010), distante a $320 \mathrm{~km}$ da região metropolitana de Belém, apresentando as coordenadas: latitude $02^{\circ} 59^{\prime} 4^{\prime \prime} \mathrm{S}$, longitude $47^{\circ} 21^{\prime} 10^{\prime}$ ' W, altitude de 90 metros e uma área aproximada de $19.342,254 \mathrm{~km}^{2}$ e a população estimada em 107.010 


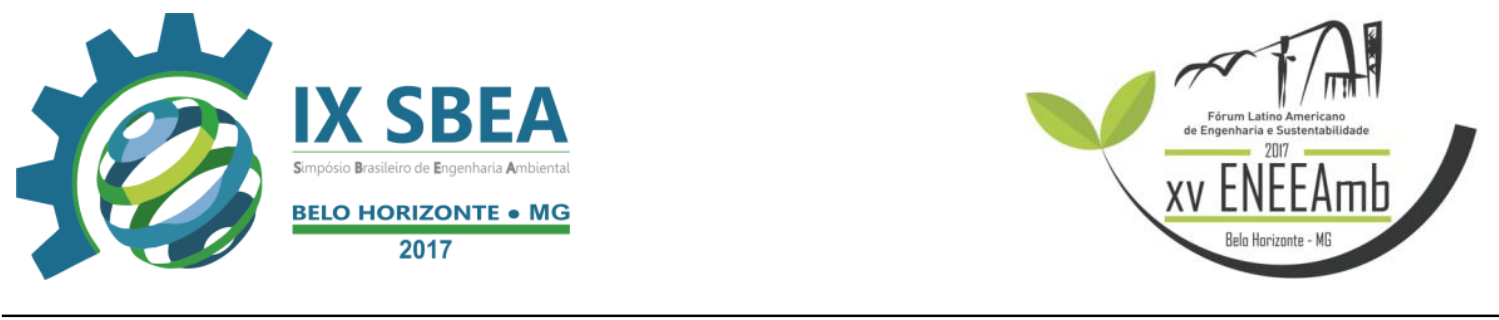

habitantes, obtendo como resultado uma densidade demográfica de 5,06 habitantes por $\mathrm{km}^{2}$ (IBGE, 2015).

Figura 01: Localização do município de Paragominas - Pará.



Disponível em: < http://www.cidades.ibge.gov.br/>

\section{RESULTADOS E DISCUSSÃO}

Os dados obtidos do estudo acerca da qualidade do ar no município de Paragominas, mostram um ambiente de melhoria, se comparado com a realidade de três décadas atrás, porém, o mesmo ainda não se encontra em um patamar ótimo e que se enquadre no cenário "verde" no qual o município se insere. O quadro 1 apresenta o formulário aplicado nas entrevistas semiestruturadas, bem como as respectivas respostas dos entrevistados. O conteúdo adquirido demonstra um conflito de ideias e opiniões no que se refere a atual condição do ar da cidade, considerada um município verde.

Quadro 1: Entrevista semiestruturada realizada no município de Paragominas.

\begin{tabular}{|c|c|c|c|}
\hline Questões & Entrevistado 1 & Entrevistado 2 & Entrevistado 3 \\
\hline $\begin{array}{c}\text { Como você } \\
\text { avalia a } \\
\text { qualidade do } \\
\text { ar no } \\
\text { município de } \\
\text { Paragominas? }\end{array}$ & $\begin{array}{c}\text { "Nos centro urbano a qualidade } \\
\text { do ar está fora dos padrões } \\
\text { estabelecidos na legislação, por } \\
\text { exemplo, no mercado } \\
\text { municipal no qual realizei } \\
\text { pesquisas." }\end{array}$ & "Boa" & $\begin{array}{c}\text { "Hoje podemos dizer } \\
\text { que a qualidade do ar é } \\
\text { boa se compararmos } \\
\text { com alguns anos atrás." }\end{array}$ \\
\hline $\begin{array}{c}\text { Em sua } \\
\text { opinião, } \\
\text { Paragominas } \\
\text { se porta como } \\
\text { município }\end{array}$ & $\begin{array}{c}\text { Não, pois não há um controle } \\
\text { eficiente das poluições } \\
\text { atmosféricas." }\end{array}$ & $\begin{array}{c}\text { "Na visão industrial, } \\
\text { sim. As indústrias } \\
\text { possuem sistemas } \\
\text { eficazes de controle da } \\
\text { poluição atmosférica. }\end{array}$ & $\begin{array}{c}\text { "Sim, pois a cidade há } \\
\text { alguns anos atrás tinha } \\
\text { muitas empresas que } \\
\text { poluíam muito e } \\
\text { algumas fecharam e }\end{array}$ \\
\hline
\end{tabular}




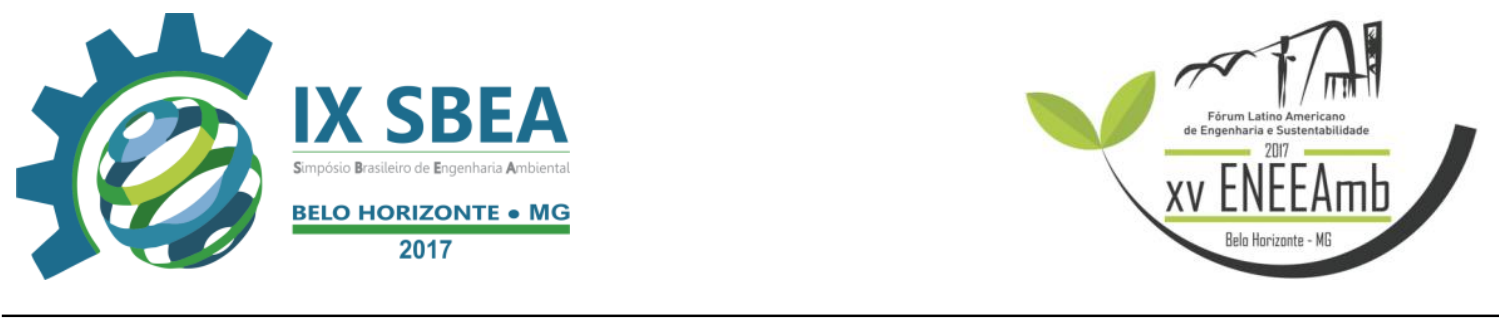

Quadro 1: Entrevista semiestruturada realizada no município de Paragominas. (Continuação)

\begin{tabular}{|c|c|c|c|}
\hline $\begin{array}{l}\text { verde no que } \\
\text { se refere à } \\
\text { poluição } \\
\text { atmosférica? }\end{array}$ & & $\begin{array}{l}\text { Quanto à gestão de } \\
\text { queimadas, a cidade } \\
\text { possui parceira com o } \\
\text { IBAMA, para o } \\
\text { combate ao incêndio." }\end{array}$ & $\begin{array}{l}\text { algumas fecharam e } \\
\text { outras mudaram para } \\
\text { outros municípios.” }\end{array}$ \\
\hline $\begin{array}{c}\text { Qual a } \\
\text { importância } \\
\text { do uso de } \\
\text { veículos } \\
\text { alternativos, } \\
\text { como por } \\
\text { exemplo, as } \\
\text { bicicletas, } \\
\text { para a } \\
\text { qualidade do } \\
\text { ar do } \\
\text { município? }\end{array}$ & $\begin{array}{c}\text { "Haveria melhoria nos índices } \\
\text { de poluição." }\end{array}$ & $\begin{array}{c}\text { “Considero irrelevante } \\
\text { o nível de poluição } \\
\text { atmosférica causado } \\
\text { por automóveis em } \\
\text { Paragominas. Porém, } \\
\text { qualquer medida que } \\
\text { reduza à máxima } \\
\text { emissão de poluentes } \\
\text { pode ser considerada } \\
\text { de grande } \\
\text { importância." }\end{array}$ & $\begin{array}{l}\text { "É de grande } \\
\text { importância, pois além } \\
\text { de não poluir a cidade, } \\
\text { ainda é fonte de } \\
\text { exercícios para as } \\
\text { pessoas." }\end{array}$ \\
\hline $\begin{array}{l}\text { Quais seriam } \\
\text { as suas } \\
\text { propostas } \\
\text { com relação à } \\
\text { diminuição da } \\
\text { poluição } \\
\text { atmosférica } \\
\text { em } \\
\text { Paragominas? }\end{array}$ & $\begin{array}{c}\text { "Fiscalização rigorosa por parte } \\
\text { de órgãos ambientais } \\
\text { competentes." }\end{array}$ & $\begin{array}{l}\text { "Intensificar o combate } \\
\text { a incêndios florestais } \\
\text { durante o verão. } \\
\text { Condicionar os } \\
\text { empreendimentos, } \\
\text { mediante a licença } \\
\text { ambiental para o uso de } \\
\text { tecnologias eficazes } \\
\text { para o controle da } \\
\text { poluição atmosférica." }\end{array}$ & $\begin{array}{l}\text { "Se algumas pessoas } \\
\text { utilizam-se alguns meios } \\
\text { de transportes } \\
\text { corretamente e se, por } \\
\text { exemplo, existissem } \\
\text { ciclovias para que as } \\
\text { pessoas usassem mais as } \\
\text { bicicletas, melhorariam } \\
\text { muito a poluição } \\
\text { atmosférica." }\end{array}$ \\
\hline
\end{tabular}

Fonte: Autores, 2017.

Segundo Oliveira et. al., a pecuária foi a principal atividade responsável pela conjuntura estrutural de desenvolvimento de parte da Amazônia brasileira (Amazônia Oriental) nas décadas de 1960 e 1970. Porém, outras atividades produtivas também emergiram com muita intensidade na região tais como a exploração de produtos florestais madeireiros, que é a base da economia de muitos municípios paraenses. Decorrente desse processo, Paragominas teve a economia fortemente aquecida pela extração de tais produtos madeireiros. Em contrapartida, com a intensa extração madeireira o município entrou no grupo de municípios que mais desmatam e que apresentam maior índices de queimadas no Brasil. A partir do ano de 2008, iniciou-se um movimento de articulação e negociação entre o Poder Público local e empresas, visando novas alternativas para o desenvolvimento urbano, nesse cenário as entidades locais decidem aderir ao projeto Paragominas Município Verde, que tem como objetivo criar uma alternativa sustentável de desenvolvimento. 


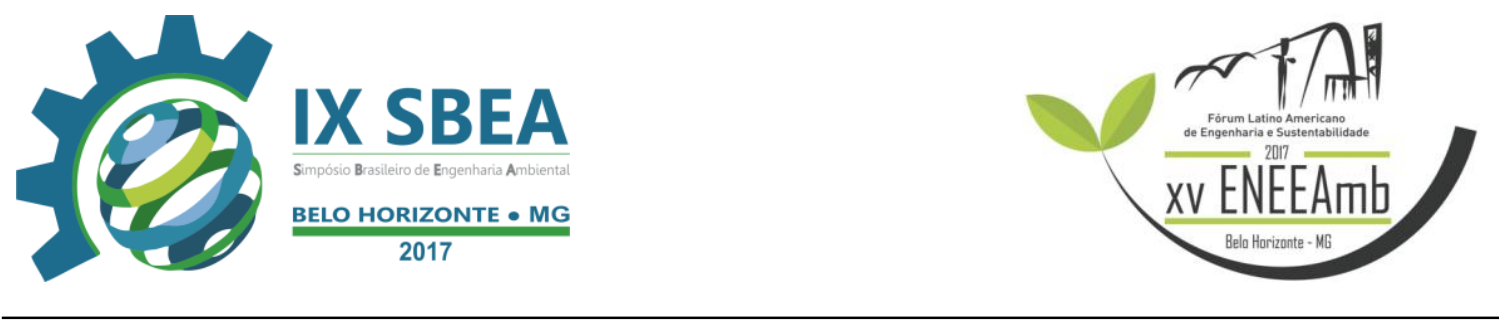

Nesse cenário, a qualidade do ar está intrinsicamente atrelada ao bom estado de outros ecossistemas, tais como o solo, que fundamenta-se em sua capacidade de atuar dentro dos limites de um ecossistema manejado ou natural, com o intuito de sustentar, por exemplo, a produtividade de animais e plantas, bem como, aumentar a qualidade do ar. Deste modo, o desmatamento de aproximadamente $45 \%$ da vegetação do munícipio de Paragominas está diretamente ligado com a diminuição da qualidade do ar da região estudada, pois, a supressão vegetal ocasiona perda da qualidade do solo e que, consequentemente, prejudica a qualidade do ar do local pela ausência de espécies arbóreas que auxiliam na manutenção do mesmo (STURMER et al., 2011).

Deste modo, a cidade de Paragominas sofreu muito com a extração de madeira e a presença exacerbada de carvoarias na cidade, fato que torna diretamente vulnerável a qualidade do ar do município. A partir do ano de 2008, por meio do Programa Municípios Verdes, a sociedade paragominense reúne esforças na tentativa de reverter o cenário ambiental negativo que a história deixou como herança. Oliveira et al. (2012), no estudo sobre variáveis sociais do município estudado, apontam que mortes ocasionadas por doenças respiratórias apresentaram um índice menor que 1 , de forma precisa 0,9775 no ano de 2010, o que corrobora com a afirmativa de tentativa de reversão do cenário obscuro que estava atrelado a cidade.

A lei municipal n. 644:2007 institui a Política Municipal do Meio Ambiente e dá outras providências no munícipio de Paragominas. A respeito da poluição atmosférica, o artigo 56 aborda que toda e qualquer atividade ou equipamento que produza fumaça, poeira, vapores químicos ou desprenda odores desagradáveis, incômodos ou prejudiciais à saúde, deverão ser instalados dispositivos para eliminar ou reduzir ao mínimo os fatores da poluição, de acordo com a legislação em vigor. Porém, a fiscalização do cumprimento ou não de tal lei é falha, em alguns casos chega a ser até inexistente, o que acaba por dificultar a ideal execução desse instrumento legal de conservação da qualidade do ar.

\section{CONCLUSÕES/RECOMENDAÇÕES}

A cidade de Paragominas sempre está em evidência no que se refere a questão ambiental, pois durante anos, era vista como uma das cidades que mais desmatavam no cenário nacional, e, atualmente, traz consigo a responsabilidade de "ser" um município 


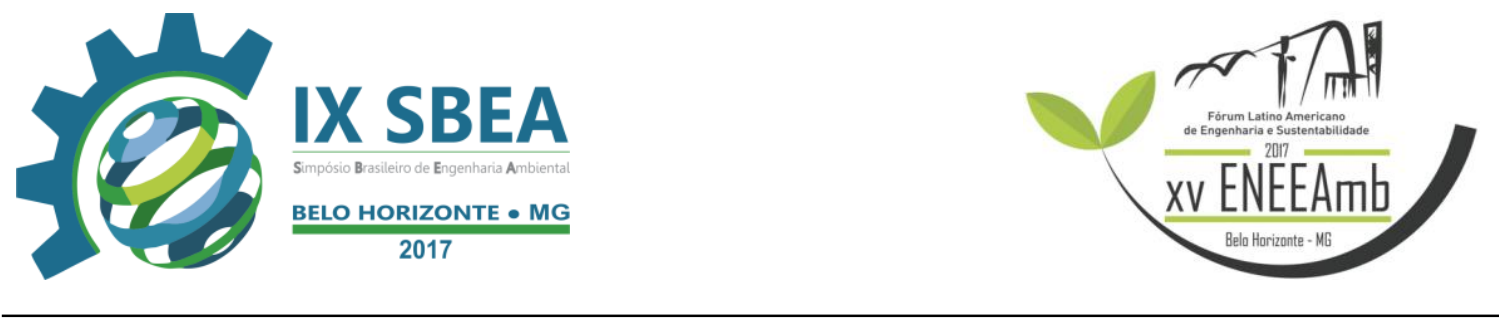

verde, o que agrega ainda mais deveres a serem cumpridos ao meio ambiente, como por exemplo, proporcionar a melhoria da qualidade do ar da região e, em consequência aumentar a qualidade de vida da população.

Nesse cenário, a poluição do ar proveniente das industrias e veículos automotores são responsáveis pelos maiores problemas de saúde humana, onde são necessárias legislações que protejam a qualidade do ar e órgãos que monitorem e fiscalizem constantemente a qualidade do ar.

Portanto, Paragominas, na atual realidade, apresenta uma qualidade do ar melhor do que há de décadas, em que o desmatamento e as atividades madeireiras e de carvoaria predominavam na região. Porém, a condição do ar ainda precisa ser melhorada, para que aquele cenário obscuro do passado seja totalmente superado, e o que município possa realmente ser chamado de "verde".

\section{REFERÊNCIAS BIBLIOGRÁFICAS}

ARBEX, M. A. et. al. A poluição do ar e o sistema respiratório. Jornal Brasileiro de Pneumologia, Brasília, v.38, n. 5, p.643-655, set.-out. 2012.

GUARIEIRO, L. L. N. et. al ; VASCONCELLOS, P. C.; SOLCI, M. C. Poluentes atmosféricos provenientes da queima de combustíveis fósseis e biocombustíveis: Uma breve revisão. Revista Virtual de Química, Salvador, v.3, n.5, p. 1-12, nov. 2011.

KLUMPP, A. et.al. A. Um novo conceito de monitoramento e comunicação ambiental: a rede europeia para a avaliação da qualidade do ar usando plantas bioindicadoras (EuroBioNet). Brasil Botânica, v.24, n.4, p.511-518, dez. 2001.

LEAL, G. C. S. et. al.; FARIAS, M. S. S., ARAÚJO, A. F. O processo de industrialização e seus impactos no meio ambiente urbano. Qualit@s Revista Eletrônica, Campo Grande, v.7, n.1, 2008.

MOURA, M. et. al. Qualidade do ar e transtornos respiratórios agudos em crianças. Revista Saúde Pública, Rio de Janeiro, v.42, n.3, p.503-511, jan. 2008.

OLIVEIRA, R. S. et. al. Da condição de município "Marrom" a município "Verde": o caso de Paragominas - PA. Revista de Administração e Negócios da Amazônia, Belém, v. 4, n. 2, p.122-139, ago. 2012.

PARAGOMINAS (Município). Constituição (2007). Lei no 644, de 14 de dezembro de 2007. Institui a Política Municipal do Meio Ambiente e dá outras providências. Disponível em: <https://www.jusbrasil.com.br/topicos/13842877/artigo-125-da-lei-n- 


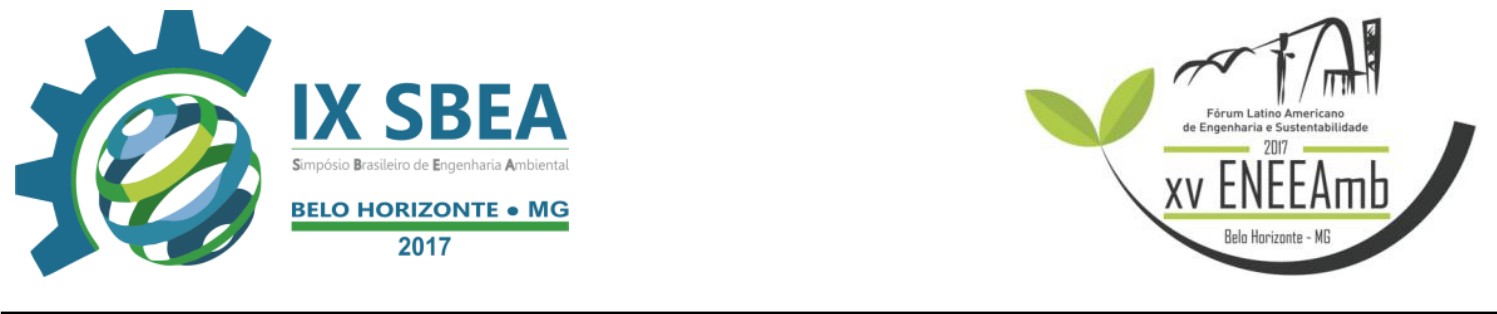

644-de-14-de-dezembro-de-2007-do-municipio-de-paragominas>. Acesso em: 13 maio 2017.

SEMA - Secretaria de Estado do Meio Ambiente. Relatório de monitoramento da qualidade do ar e agravos à saúde relacionados com a poluição atmosférica. Mato Grosso,.2008..Disponível em:. <http://www.sema.mtgov.br/index.php?option=com_cont ent\&view=article \&id=2294\&Itemid=360> . Acesso em: 24 abr. 2017.

STURMER, S. L. K. et. al. Variações nos teores de carbono orgânico em função do desmatamento e revegetação natural do solo. Ciência Florestal, Santa Maria, v.21, n.2, p.241-250, abr.-jun. 2011. 